explain the scope and nature of the book. As the author explains in his preface, the present edition naturally cannot differ greatly in its text from its predecessor, but instead of putting the work to press without any changes he has seized the opportunity to insert additional illustrations and a coloured plate and has altered and added to the text wherever he thought that such additions would be advantageous. We still think that some further alterations are neeojed in the chapter referring to examination of the lings; if the student were to follow Dr. Hare's instructions only he would probably fall into error. An assemblage of signs and progression of symptoms is not sufficiently insisted on. We believe that wrong diagnoses as regards the absence or presence of pulmonary tuberculosis lie more in commission than omission - that is to say, that certain physical signs are taken for those of disease when the lungs are perfectly bealthy, owing to a want of appreciation of the variations in the breath sounds over various parts of the thorax. Taking the book on the whole, however, it is a most valuable one and would form a good addition to a practitioner's library.

Constipation and its Modern Treatment. By GEORGE HERSCHell, M.D. Lond. Second edition. London: Henry J. Glaisher. 1899. Pp. 91. Price 2s. 6d.-The title of this little book is rather misleading, for (as the author admits in his preface) it does not profess to be an exhaustive treatise upon the subject of constipation, but merely contains a description of certain methods of diagnosis and treatment. A perusal of it, however, will give much information as regards the management of obstinate cases of constipation-those in which drug treatment has been tried in vain. The usual therapeutical measures are not more than mentioned, whereas certain mechanical methods are described in full. The most satisfactory way of administering enemata, for instance, is minutely given and practitioners would do well to give more particular instructions, on the lines laid down by Dr. Herschell, to their patients and nurses when this procedure is necessary, for the ordinary manner in which an enema is given is often productive of very little result. The author is of opinion that ordinary massage has been much over-rated as an agent in the treatment of atony of the intestines, as it has disadvantages which should prevent its routine use in every-day practice; on the other hand, he speaks in high terms of the use of "vibration" as a therapeutic agent. This treatment, however, would probably be required only in very exceptional cases.

Anatomischer Atlas der Geburtshilfichen Diagnostik und Therapie (Anatomical Ltlas of Obstetrical Diagnosis and Treatment). By Dr. OsCAR SchatefFer With 160 Plates, many coloured, and numerous Illustrations in the text. Second edition. Crown 8ro. Munich: J. F. Lehmann. 1899. Pp. 318. Price 12 marks.-Atlas und Grundriss der Gynäkologie (Atlas and Essentials of Gynacology). By Dr. OSCAR SCHAEFFER. With 207 Plates, many coloured, and 62 Illustrations in the text. Second edition. Crown 8 vo. Munich : J. F. Lehmann. 1899. Pp. 262. Price 14 marks.The fact that a second edition of these two books has appeared after an interval of but two years seems to show that they have met a demand in their own country. Both of them have been considerably enlarged and many new plates and illustrations have been added. As we said in noticing the English translation of the first edition, an attempt is made to combine a text-book and an atlas and the result to our mind is not a great success. Some of the new figures are of considerable merit, but they show a want of accuracy which shakes our faith in them not a little as faithful representations of the conditions which they are supposed to illustrate. One of the most striking examples of this inaccuracy is seen in the preposterous anatomical tigure intended to represent the measurement of the external conjugate by means of callip:rs. Many of the plates, however, are of interest and have a certain value as representing original clinical or post-mortem specimens. The letterpress suffers from too much condensation and the constant interpolation of descriptions of the illustrations is very annoying to the eye. We feel that it is extremely improbable that the second edition, should it be translated, will make any greater appeal to the English student than we imagine the first edition has done.

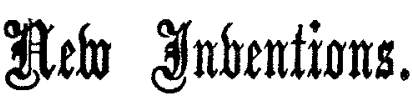

STERILISED OPHTHALMIC DRESSINGS.

$\mathrm{BY}$ the aid of a portable steriliser it is an easy matter in private practice to render aseptic the various instruments required for an ophthalmic operation; but to be thorough the sponges used for removing blood, lens matter, \&c., and the pads of Gamgee tissue applied as a dressing should equally be placed beyond suspicion, and this is less simply brought. about. The following method will, I think, be found to. answer the purpose, besides being a great saving of time and trouble. I am well satisfied with the manner in which Messrs. Ferris and Co. of Bristol have carried out my instructions. A number of circular pads of absorbent tissue. are cut and placed in a tin, each pad being separated from its fellow by a leaf of paper. To these is added a tray containing "swabs" or sponges made of small rolls of lint, the whole being then placed in a suitable steam steriliser. Here a pressure of $20 \mathrm{lb}$. to the square inch and a temperature of from $120^{\circ} \mathrm{C}$. to $130^{\circ} \mathrm{C}$. are produced and maintained for a sufficient time to ensure absolute sterilisation. The tins are then removed and hermetically sealed. The form of tin employed is similar to that used by Messrs. Wills and Co. for putting up tobacco and cigarettes. and is opened in a like manner by a cutter in the cover. Each tin contains 20 pads and a sufficient number of swabs for an operation. By this means the surgeon procures his dressings ready cut, sterilised, and packed - a great con$v \in$ nience in emergency operations - the pads retain their shape and do not adhere to one another, and each can be removed singly without touching the remainder. The price of the tins is $18 \mathrm{~s}$. per dozen and the makers are Messrs. Ferris and Co. of Bristol, from whom they can be obtained.

K. C. CHETWOOD-AIKEN,

Ophthalmic Surgeon to the Royal Cornwall Infirmary.

\section{A MODIFIED NASAL SPECULUM.}

THE Duplay nasal speculum has two disadvantages. It is difficult to clean thoroughly and occasionally it is apt to be in the way during an operation. Thus, in the removal of certain varieties of polypi, after the speculum has been used to facilitate the application of the snare it would be an undoubted advantage if during the actual operation it could be removed from the nose. To permit of this I have had it. modified by the addition of a couple of small screws, so that it can be readily separated into halves and freed from the snare at the will of the user. After a fair experience I am satisfied that the modification is an improvement on the ordinary instrument. It has been made for me by Messrs. Foung and Son of Forrest-road, Edinburgh.

$\begin{array}{ll}\text { Edinburgh. } & \text { G. HUNTER MACKENZIE, M.D. Edin. }\end{array}$

Drainage of Truro-At the meeting of the Sanitary Committee of the Cornwall County Council held on Oct. 20th it was reported that the Local Government. Board had written stating that they proposed to hold an inquiry at Truro on the complaint that the local authority had been neglectful of the drainage.

Royal Humane Soctety's Awards.-Among the awards recently made by the Royal Humane Society was a testimonial to Alfred Mitchell of Polruan (Cornwall) for rescuing Mr. Frederick King Green, surgeon to the Royal United Hospital, Bath, who, while bathing at Polruan on July 8th, found himself unable to regain the shore. 